\title{
CARACTERIZAÇÃO SOCIAL E TECNOLÓGICA DA PRODUÇÃO DE UVAS PARA MESA EM PEQUENAS PROPRIEDADES RURAIS DA REGIÃO DE JALES-SP ${ }^{1}$
}

\author{
THIAGO VIEIRA DA COSTA², MARIA APARECIDA ANSELMO TARSITANO ${ }^{3}$, \\ MARCO ANTONIO FONSECA CONCEIÇÃO ${ }^{4}$
}

RESUMO-A viticultura é uma atividade relevante para os produtores rurais do Estado de São Paulo, sobretudo aqueles detentores de pequenas áreas. O presente trabalho teve como objetivo caracterizar os principais aspectos sociais e tecnológicos utilizados na produção de uvas para mesa na região de Jales (SP). Os dados foram levantados nos anos de 2009 e 2010, a partir da aplicação de questionários a 19 produtores de uva e do acompanhamento do ciclo de produção de 10 propriedades. Os produtores cultivam pelo menos três cultivares diferentes de uva, sendo as principais: 'Niagara Rosada', 'Itália' e 'Benitaka'. A área média das propriedades é de, aproximadamente, 21 ha, e a área média com parreiras de uva é de 2,4 ha. A maioria dos produtores não conta com assistência técnica regular, não segue recomendações de adubação e não emprega critérios técnicos para o manejo da irrigação. O controle de doenças é realizado de forma preventiva e intensa, chegando a superar 100 aplicações por ciclo, no caso das uvas finas para mesa. Os resultados devem subsidiar a realização de outras pesquisas, assim como programas de planejamento e transferência de tecnologia, proporcionando ao produtor um manejo mais adequado da cultura, bem como o desenvolvimento sustentável rural regional.

Termos de indexação: viticultura, videira, fitossanidade, irrigação.

\section{SOCIAL AND TECHNOLOGICAL CHARACTERIZATION OF TABLE GRAPE PRODUCTION IN SMALL PROPERTIES IN JALES REGION-SP}

\begin{abstract}
Viticulture is an important activity for small farmers of the state of São Paulo, Brazil. This study aimed to characterize the social and technical aspects used in table grapes production in Jales region (SP). The data were collected in 2009 and 2010 from questionnaires answered by 19 grape growers and by monitoring the production cycle of 10 properties. The farmers cultivate at least three different grape cultivars and the main ones are 'Niagara Rosada', 'Italia' and 'Benitaka'. The properties size averages around 21 ha and the average grapevine area is 2.4 ha. Most producers do not have regular technical assistance; neither follows recommendations for fertilizer application nor employs technical criteria for irrigation management. The disease control is carried out preventively and intensively, surpassing 100 applications per cycle, in the case of fine table grapes. The results should support other researches, as well planning programs and technology transfer, providing the producer a more appropriate culture management, as well as regional rural sustainable development.
\end{abstract}

Index terms: viticulture, grapevine, plant disease, irrigation.

\footnotetext{
${ }^{1}$ (Trabalho 072-12). Recebido em: 30-01-2012. Aceito para publicação em: 10-05-2012.

2Eng. Agrônomo, mestrando da UNESP Campus de Ilha Solteira. E-mail: thi_grilo@yahoo.com.br

${ }^{3}$ Docente do Departamento de Fitotecnia, Tecnologia de Alimentos e Sócio-Economia, FEIS/UNESP, C.P. 31, 15385-000. Ilha Solteira-SP. Brasil. E-mail: maat@agr.feis.unesp.br

${ }^{4}$ Pesquisador Embrapa Uva e Vinho unidade de Jales. E-mail: marcoafc@cnpuv.embrapa.br
} 


\section{INTRODUÇÃO}

A viticultura brasileira desenvolvida em condições temperadas, comumente, segue os mesmos procedimentos utilizados em países tradicionais no cultivo da videira. Já nas regiões de clima quente, adaptaram-se técnicas de manejo a cada situação específica.

De modo geral, a viticultura paulista, com uma produção de 191.122 toneladas em 2010, tem como principais regiões produtoras, Itapetininga $(33,31 \%)$, Campinas $(31,9 \%)$, Jales $(15,1 \%)$ e Sorocaba $(11,9 \%)$, apresentando dois mercados com cadeias produtivas distintas, que são a produção de uvas comuns e finas para mesa, e uvas para vinhos, sendo que $99,2 \%$ deste total é destinado para o mercado de frutas para mesa (IEA, 2011).

A viticultura é uma atividade relevante para os produtores de Jales, sobretudo aqueles detentores de pequenas áreas. A produção de uvas finas para mesa (Vitis vinifera) na região é representada, principalmente, por cultivares como a Itália e suas mutações (Rubi e Benitaka), enquanto a principal representante das uvas comuns para mesa (Vitis labrusca) é a cultivar Niagara Rosada (COSTA et al., 2008). Essa produção exige grande conhecimento técnico, sendo a irrigação, o uso de reguladores vegetais e o sistema de podas fundamentais para a produção de frutas com qualidade e fora da época de produção de outras tradicionais regiões produtoras.

A viticultura tem mostrado condições de gerar renda, de manter os produtores no campo, de dar emprego aos seus filhos e de proporcionar condições econômicas para a manutenção das famílias nas pequenas propriedades da região. Por essa razão, muito embora dificuldades com os altos custos de produção e a queda nos preços verificada nos últimos anos venham desestimulando muitos produtores, outros apostam em novas variedades e novas tecnologias de produção.

No entanto, para o desenvolvimento e a transferência dessas novas variedades e tecnologias, devem-se conhecer o perfil dos produtores e os sistemas de produção adotados na região. Assim, a presente pesquisa teve como objetivo caracterizar os principais aspectos sociais e tecnológicos das áreas produtoras de uvas para mesa na região de Jales, noroeste do Estado de São Paulo.

\section{MATERIAL E MÉTODOS}

O estudo foi realizado na área de abrangência do EDR (Escritório de Desenvolvimento Rural) de Jales, uma das 40 Unidades Administrativas da Coordenadoria de Assistência Técnica Integral (CATI)/ Secretaria de Agricultura e Abastecimento do Estado de São Paulo, situado na região noroeste do Estado de São Paulo.

A escolha da região baseou-se no fato de uma das três unidades que compõem o Centro Nacional de Pesquisa de Uva e Vinho - CNPUV, localizado em Bento Gonçalves-RS, pertencente à Empresa Brasileira de Pesquisa Agropecuária Embrapa, estar localizado no município de Jales, a qual atuou como parceira no desenvolvimento da pesquisa, além de ser o maior polo produtor de uvas de mesa da região noroeste do Estado de São Paulo.

A seleção dos produtores que fizeram parte da pesquisa contou com a colaboração de profissionais do EDR de Jales e da Empresa Brasileira de Pesquisa Agropecuária (Embrapa), visando a levantar questões gerais e de ordem logística para a realização da pesquisa. Como critério de seleção, priorizaram-se os produtores que apresentavam diferenças em relação à área cultivada, técnicas de cultivo, variedades, formas de comercialização da fruta, que tivessem um mínimo de organização para que as informações pudessem ser levantadas e que mostrassem interesse em participar da pesquisa.

Os dados foram levantados em 2009 e 2010, a partir da elaboração e aplicação de questionários. O método utilizado para levantar os dados foi a entrevista presencial e semi-estruturada, aplicada a uma amostra de 19 produtores, sendo que, destes, 10 foram acompanhados mensalmente. Visando a atender aos objetivos listados no projeto, inicialmente, foi realizado um pré-teste, para melhor adequação dos questionários.

Os itens abordados foram parâmetros socioeconômicos: faixa etária, nível de escolaridade, tempo de trabalho na agricultura, área da propriedade, área ocupada com a viticultura, formas de organização coletiva, assistência técnica, fonte de recursos financeiros, mão de obra utilizada, problemas, dificuldades e parâmetros tecnológicos: adubação, sistemas de poda, condução e irrigação, variedades cultivadas, manejo fitossanitário de pragas e doenças, quantidade utilizada de defensivos, número e formas de aplicação. 


\section{RESULTADOS E DISCUSSÃO}

\section{Caracterização dos produtores de uva da região}

A maior parte das propriedades pesquisadas (7) pertence ao município de Jales, enquanto as outras são de Urânia (5), Palmeira D’Oeste (4), Santa Salete (2) e Aspásia (1). Quase $90 \%$ do total residem nas propriedades, evidenciando que a viticultura fixa o homem no campo. A média de idade dos produtores foi de 49 anos, variando de 26 a 66 anos de idade, indicando que a maioria destes se encontra em idade produtiva.

Quanto ao índice de escolaridade, optou-se por classificá-la segundo a nomenclatura anterior de ensino (Figura 1). Dentre os produtores entrevistados, 10,5 \% possuem Ensino Fundamental de $1^{\mathrm{a}}$ a $4^{\mathrm{a}}$ série, $31,6 \%$ o Fundamental de $5^{\mathrm{a}}$ a $8^{\mathrm{a}}$ série, $5,2 \%$ possuem Ensino Médio $1^{\mathrm{a}}$ a $2^{\mathrm{a}}$ anos, 42,1\% o Médio completo, apenas 1 produtor possui Ensino Superior incompleto e 1 Ensino Superior completo.

O tempo médio de experiência dos produtores com a cultura da uva foi de 17 anos, variando de 6 a 25 anos, o que indica a forte tradição regional com a atividade (Figura 2). Todos os produtores pesquisados produzem uva em terra própria, sendo a área média das propriedades igual a 20,9 ha, variando de 2,1 ha a 52,8 ha. A área média com parreiras de uva foi de 2,4 ha, variando de 0,35 ha a 8 ha.

Das formas de organização coletiva de produtores, 52,6\% relataram estar envolvidos com alguma forma de organização, sendo que, destes, 30 \% estão ligados a cooperativas e 70\% participam de associações. Quanto à assistência técnica, $84 \%$ dos produtores não contam com nenhum acompanhamento técnico, enquanto os demais contratam assistência técnica particular. Quando necessitam, os produtores que não têm assistência buscam auxílio técnico na Casa da Agricultura local e nas revendas de produtos agropecuários da região.

Aproximadamente $74 \%$ dos produtores utilizam financiamento, sendo que, destes, cerca de $14 \%$ possuem mais de um financiamento. As fontes de financiamento podem ser observadas na Figura 3. A maioria, ou seja, 64\%, utiliza recursos do Pronaf (Programa Nacional de Fortalecimento da Agricultura Familiar), 22\% utilizam recursos do PROGER (Programa de Geração de Emprego e Renda), 28\% optam por financiamento através de empresa privada. Os recursos foram direcionados para custeio de produção, aquisição de trator ou pulverizador.

\section{Adubação}

Quando perguntado ao produtor sobre a realização de análise do solo, $84 \%$ responderam afirmativamente, dentre estes $37,5 \%$ adubam de acordo com a recomendação, 37,5\% seguem parcialmente as recomendações, geralmente aplicando quantidades maiores, e $25 \%$ não seguem a recomendação. O intervalo médio observado para a realização de análise de solo foi de 1 a 3 anos, sendo esta análise realizada anualmente por mais de $50 \%$ dos produtores. A análise foliar é realizada por apenas 15,8\% dos produtores em intervalos que variam de 1 a 3 anos.

$\mathrm{O}$ receio de não produzir tem levado os produtores a aplicações excessivas de nutrientes. A não consideração dos resultados obtidos nas análises vem causando problemas relacionados ao excesso de nutrientes e desequilíbrio destes no solo.

A aplicação de fertilizantes e adubos sem a recomendação adequada, sem a compreensão completa de como estes vão afetar, no longo prazo, a fertilidade dos solos de sistema convencional em grandes áreas, é preocupante,e muitos destes nutrientes podem ser carreados até corpos d'água e causar poluições severas. O uso excessivo de fertilizantes fosfatados e nitrogenados causam a eutrofização de águas (DARILEK et al., 2009).

\section{Época de podas}

Para que a produção da videira na região noroeste do Estado de São Paulo ocorra no período de entressafra (julho a novembro) de outras regiões tradicionais, o manejo de podas é diferenciado dos demais pólos produtores. Além da poda de produção é necessária a realização da poda de formação, que tem por finalidade preparar a planta para o próximo ciclo de produção.

De acordo com dados levantados, a época da poda de formação (agosto a dezembro) variou de 15 a 60 dias após a colheita, sendo que 37\% dos produtores entrevistados realizam esta poda 30 dias após a colheita. Com relação à época da realização da poda de produção (fevereiro a junho), as respostas variaram muito, podendo-se destacar, no entanto, que cerca de $37 \%$ dos produtores entrevistados indicaram março como o mês para realização dessa poda. O intervalo médio relatado entre a poda de produção e a colheita para as uvas finas é de, aproximadamente, 150 dias e de 110 dias para a 'Niagara Rosada'.

\section{Irrigação}

O sistema de irrigação por microaspersão é utilizado em $68 \%$ das parreiras, e $32 \%$ dos produtores apresentam 2 tipos de sistemas (microaspersão e aspersão por subcopa). Apenas um produtor relatou 
utilizar sistema de irrigação por microaspersão e gotejamento.

O manejo da irrigação visa a aplicar água à cultura na quantidade certa, no momento adequado. Entretanto, o uso das tecnologias disponíveis para adequado manejo da irrigação ainda não é uma realidade na região. O método mais utilizado para tomada de decisão é a verificação da umidade do solo, sendo esta avaliada através da retirada de uma pequena quantidade da superfície do solo. Essa metodologia é utilizada por $78 \%$ dos produtores como parâmetro de tomada de decisão quanto à necessidade de irrigação, sendo que os demais produtores utilizam intervalos fixos entre irrigações. Esse intervalo varia conforme o sistema de irrigação sendo, em média, de 2 a 3 vezes por semana quando se utiliza o sistema de microaspersão, e de 1 ou 2 vezes por semana no sistema de aspersão.

A maioria dos produtores $(94,7 \%)$ possui pluviômetro, no entanto em nenhum dos casos é realizado cálculo para descontar a água da chuva na irrigação. Em nenhuma propriedade foi encontrado hidrômetro para medir a quantidade de água usada na irrigação. Além do pluviômetro, alguns produtores (21\%) possuem termômetro para medir a temperatura ambiente, entretanto eles relataram não utilizar este equipamento como forma de apoio no manejo da cultura.

A aplicação de adubos via água de irrigação, conhecida como fertirrigação, é uma tecnologia ainda não empregada pelos produtores participantes da pesquisa. A utilização desta tecnologia pode ser uma forma de aumentar a eficiência da adubação (PIRES et al., 2011), e do sistema de irrigação com economia de mão de obra. Os córregos presentes na região, em sua maioria, são de pequeno porte, o que pode ser um fator limitante para a utilização da água de irrigação. Entretanto, dentre os produtores pesquisados, nenhum relatou problemas com falta de água para irrigação.

\section{Principais Cultivares}

$\mathrm{O}$ número de cultivares plantadas em uma mesma propriedade variou de 1 a 6 , sendo que $84,2 \%$ dos produtores tinham ao menos 3 cultivares . A cultivar com maior área dentre os produtores pesquisados é a 'Niagara Rosada'(13,6 ha), seguida da 'Itália' (6,8 ha).

Devido à maior resistência à incidência de doenças e de não necessitar da operação de raleio dos cachos, a demanda por mão de obra da 'Niagara Rosada' é menor, sendo este um dos principais fatores que justificam a expansão desta cultivar na região.

A 'Itália’ é cultivada por 73,7\% dos produto- res (Figura 4), seguida das cultivares Benitaka e Niagara Rosada, presentes em $63,1 \%$ das propriedades. As cultivares Bordô, Isabel e Cabernet Sauvignon, utilizadas principalmente para produção de vinho e suco, estão presentes em apenas uma propriedade cada, o mesmo acontecendo com as 'BRS Morena' e 'BRS Clara, cultivares sem sementes lançadas pela Embrapa Uva e Vinho.

A produtividade das parreiras da região pode ser considerada alta. Dentre os produtores pesquisados, a produção média por hectare das cultivares Itália, Rubi e Benitaka foi de, aproximadamente, 35,0 toneladas, e para as cultivares Centennial Seedless e Niagara Rosada foi de 25,0 e 20,5 toneladas, respectivamente.

\section{Manejo Fitossanitário}

As principais doenças encontradas em uvas finas foram: Míldio - Plasmopara vitícola (100\%), Oídio - Uncinula necator (100\%), Requeima das folhas - Alternária sp.(85\%), Botriodiplodiose - Botryosphaeria spp. (61\%), Podridões do cacho - Melanconium fuligineum (61\%) e Antracnose Elsinoe ampelina (30\%).

Quanto à uva comum 'Niagara Rosada', as principais doenças foram: Requeima das folhas Alternária sp.(100\%), Míldio - Plasmopara vitícola (83\%), Antracnose - Elsinoe ampelina (50\%) e Ferrugem Phakopsora euvitis Ono (50\%). A Figura 5 mostra as principais doenças encontradas em uvas finas e comuns.

O tratamento preventivo realizado pelos produtores da região é baseado no estádio fenológico da planta. Fundamenta-se em um manejo intensivo durante o período de brotação, que é período mais crítico para o controle de doenças. Com o decorrer do ciclo, as pulverizações ficam mais espaçadas.

$\mathrm{O}$ número médio de pulverizações para uva comum foi de 59, enquanto para as uvas finas, devido à maior suscetibilidade, essa média sobe para 103 pulverizações por ciclo de produção. Há grande preocupação com a racionalização e minimização do uso de defensivos, sendo que o excesso de pulverizações pode trazer diversos danos ambientais. Rosa et al. (2007) consideram que o uso de indutor de resistência Agro-Mos + Crop-set é uma das ferramentas que podem ser utilizadas no manejo do controle da doença, para reduzir o número de aplicações de fungicidas e, consequentemente, o impacto ambiental.

Diferentemente do que ocorre com as doenças, o monitoramento de pragas é realizado pela maioria dos produtores. De acordo com os dados da pesquisa, $68,4 \%$ dos produtores realizam monitoramento de pragas e apenas $31,6 \%$ optam pelo controle preven- 
tivo. Entretanto, nenhum produtor relatou haver uma frequência exata para realizar este monitoramento, que ocorre durante a realização dos diferentes tratos culturais da cultura.

As principais pragas encontradas nas parreiras de uva fina foram: Ácaro-Rajado - Tetranucus urtica (100\%), Ácaro-Branco - Polyphagotarsonemus latus (84,6\%), Cochonilhas (69,2\%), Formigas-Cortadeiras (53,8\%), Mosca-das-Frutas - Anastrepha fraterculus (76,9\%) e Pulgão - Daktulosphaira vitifoliae (61,5\%).

No relativo à uva comum 'Niagara Rosada', as principais pragas encontradas foram: Cochonilhas $(83,3 \%)$, Formigas-Cortadeiras $(66,6 \%)$, Ácaro-Rajado - Tetranucus urticae (50\%), Ácaro-Branco - Polyphagotarsonemus latus (50\%), Pulgão - Daktulosphaira vitifoliae (50\%) e Mosca-das-Frutas - Anastrepha fraterculus (33,3\%).

Quando questionados sobre o uso do Equipamento de Proteção Individual (EPI), a maior parte dos produtores (52\%) relatou não utilizá-los, enquanto $16 \%$ dizem usar raramente e $32 \%$ utilizam o EPI em todas as pulverizações com defensivos. A principal justificativa para o não uso do EPI é o desconforto.

Formolo et al. (2011) relatam que os principais problemas enfrentados para implementar estratégias de manejo de pragas no cultivo de uvas finas para mesa são a ausência de metodologias confiáveis para o monitoramento e o reduzido número de inseticidas autorizados para a fruta, além da falta de assistência técnica. A ocorrência de pragas e doenças na cultura pode gerar grandes perdas e tornar-se fator limitante à viticultura na região. Nesse sentido, a realização de pesquisas que visem à adequação do correto manejo das diversas pragas e doenças que atacam a cultura é fundamental para viabilização de manejos mais eficientes, com redução de custos e riscos ao meio ambiente.

\section{Mão de Obra}

Além da mão de obra familiar utilizada por todos os produtores, o empregado permanente está presente em 57,9\% das propriedades na condução das parreiras, seguido por diaristas em $47,36 \%$. O sistema de parceira ocorre em 26,3\% das parreiras e 21\% dos produtores utilizam somente mão de obra familiar. A contratação de diaristas ocorre principalmten para as atividades de desbrota, desbaste dos cachos e colheita.

A falta de mão de obra qualificada é um dos problemas apontados pelos produtores como fator limitante para expansão da cultura na região. Verifica-se que, embora a atividade seja considerada como uma alternativa para agricultura familiar, esta tem exigido mão de obra além da disponível pelas famílias.

\section{Problemas e dificuldades}

Os problemas e dificuldades relacionados à cultura da uva, apontados pelos produtores, são diversos. Entretanto, o manejo de doenças (31,6\%), a comercialização $(26,3 \%)$ e a mão de obra $(15,8 \%)$ foram os mais relatados. Além desses, foram relatados também problemas na formação de cachos, ataque de ácaros, excesso de chuvas e a falta de interesse dos filhos na continuidade da atividade. No entanto, apesar das dificuldades, $26,3 \%$ dos produtores mostraram-se satisfeitos com a atividade, declarando não ter interesse em outra, e 21\% gostariam de aumentar a área com uva. 


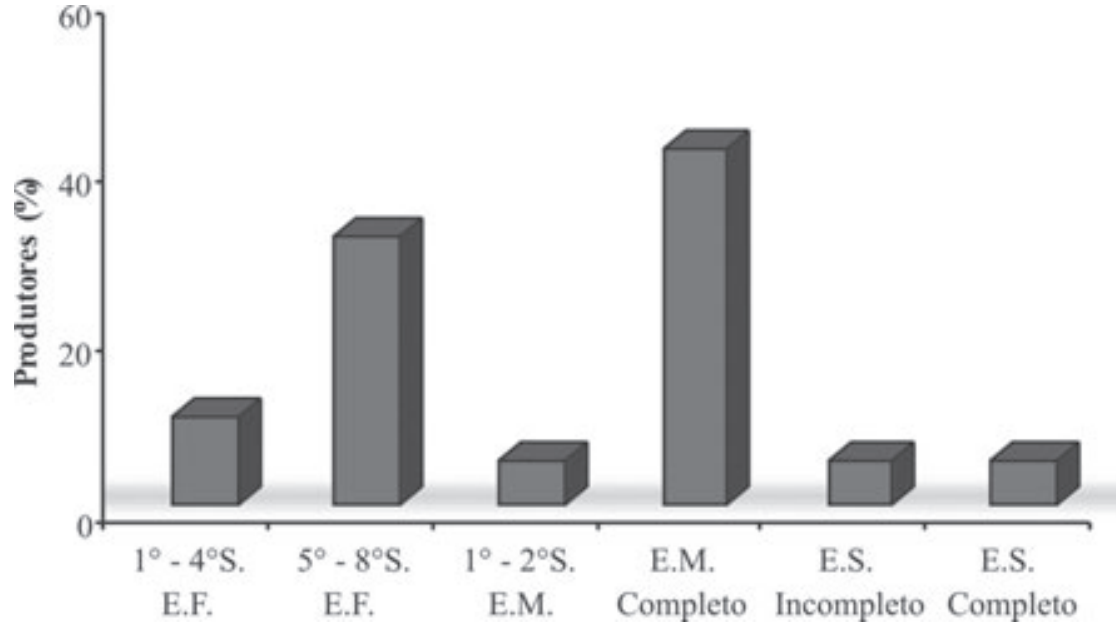

FIGURA 1- Grau de escolaridade dos produtores de uva, na área do EDR de Jales-SP, 2008/2009.

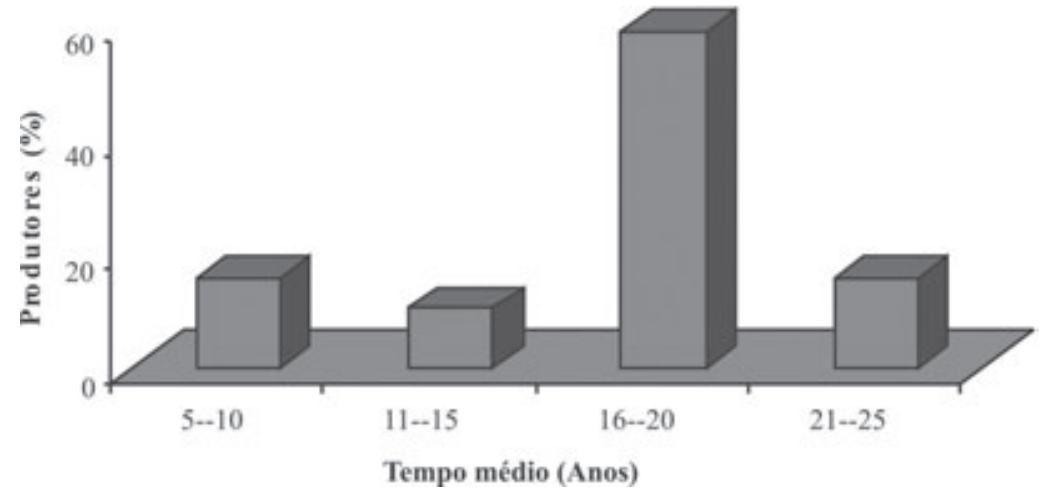

FIGURA 2-Experiência dos produtores de uva na área do EDR de Jales-SP, 2008/2009.

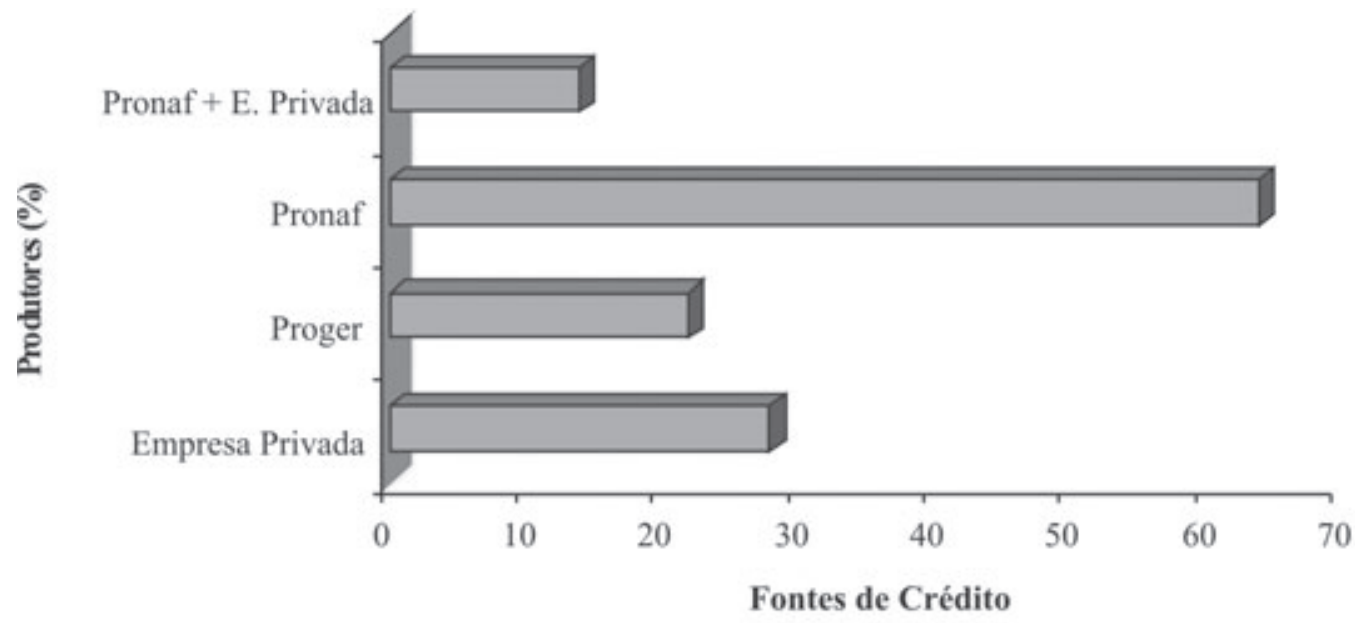

FIGURA 3- Experiência dos produtores de uva na área do EDR de Jales (SP), 2008/2009. 


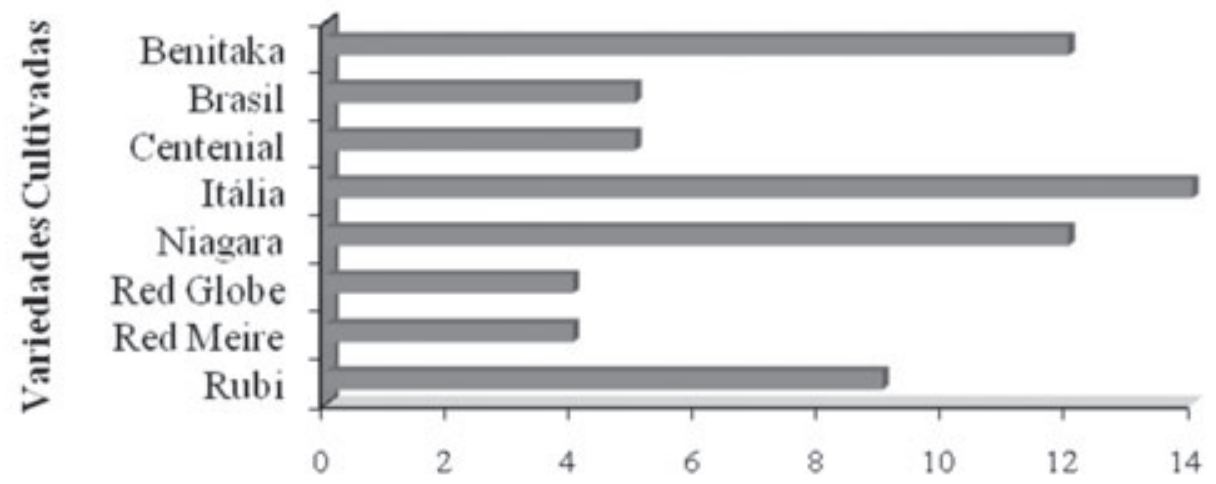

Número de Produtores

FIGURA 4-Principais variedades de uva cultivadas pelos produtores do EDR de Jales (SP), 2009.

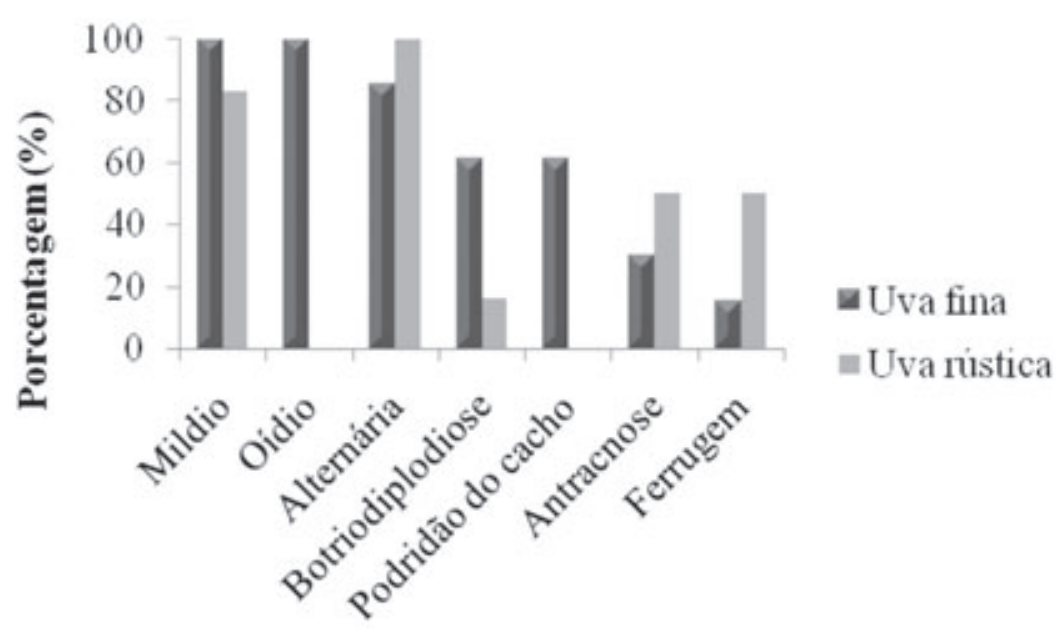

FIGURA 5- Principais doenças encontradas em uvas finas e rústicas na área do EDR de Jales (SP), 2009.

\section{CONCLUSÕES}

1- A área média das propriedades é de, aproximadamente, 21 ha, e a área média com parreiras de uva é de 2,4 ha.

2- A maioria dos produtores (52,6\%) está envolvida com alguma forma de organização coletiva.

3- A grande maioria (84\%) não conta com assistência técnica regular.

4- Os produtores cultivam, pelo menos, três cultivares de uva, sendo as principais 'Niagara Rosada’, 'Itália’ e ‘Benitaka’.

5- A maioria dos produtores faz análise de solo, mas nem sempre seguem as recomendações de adubação.
6- O sistema de irrigação predominante é por microaspersão, entretanto os produtores não empregam critérios técnicos para o manejo da água.

7- O controle de doenças é realizado de forma preventiva e intensa, chegando a superar 100 aplicações por ciclo, no caso das uvas finas para mesa.

8- Os resultados devem subsidiar a realização de outras pesquisas, assim como programas de planejamento e transferência de tecnologia, proporcionando ao produtor um manejo mais adequado da cultura, bem como o desenvolvimento sustentável rural regional. 


\section{REFERÊNCIAS}

COSTA, S.M.A.L; GOMES, M.R.L.; TARSITANO, M.A.A. A comercialização de uvas finas na região de Jales - SP. Revista Brasileira de Fruticultura, Jaboticabal, v.30, n.1, p.127-132, 2008.

DARILEK, J. L. et al. Changes in soil fertility parameters and the environmental effects in a rapidly developing region of China. Agriculture, Ecosystems and Environment, Amsterdam, v. 129, p. 286-292, 2009.

FORMOLO, R. ;RUFATO, L.; BOTTON, M.; MACHOTA JÚNIOR, R. Diagnóstico da área cultivada com uva fina de mesa (Vitis vinifera L.) sob cobertura plástica e do manejo de pragas. Revista Brasileira de Fruticultura, Jaboticabal, v. 33, n. 1, p. 103-110, 2011.
IEA - Instituto de Economia Agrícola. Banco de dados IEA. Brasília: Ministério da Integração Nacional, 2010. Disponível em: <http://www.integracao.gov. br>. Acesso em: 29 set. 2011.

PIRES, R.C.M.; FURLANI, P.R.;RIBEIRO,R.V.; JÚNIOR, D.B.;SAKAI, E.; LOURENÇÃO, A. L.; NETO, A.T. Irrigation frequency and substrate volume effects in the growth and yield of tomato plants under greenhouse conditions. Scientia Agricola, Piracicaba, v. 68, n. 4, 2011.

ROSA, R.C.T.; COELHO, R.S.B.; TAVARES, S.C.C.H.; CAVALCANTI, V.A.L.B. Efeito de indutores no controle de míldio em Vitis labrusca. Summa Phytopathologica, Botucatu, v.33 n.1, p.68-73, 2007. 